\title{
A Revised Survey on Autonomy Awareness of Foreign Language Learners in China
}

\author{
Hongbo Qi \\ Eastern Institute of Technology Data Science and Communication College, Zhejiang Yuexiu University, Shaoxing, China \\ Email: 20141076@zyufl.edu.cn
}

How to cite this paper: Qi, H. B. (2022). A Revised Survey on Autonomy Awareness of Foreign Language Learners in China. Open Journal of Modern Linguistics, 12, 44-55. https://doi.org/10.4236/ojml.2022.121005

Received: January 15, 2022

Accepted: February 6, 2022

Published: February 9, 2022

Copyright $\odot 2022$ by author(s) and Scientific Research Publishing Inc. This work is licensed under the Creative Commons Attribution International License (CC BY 4.0).

http://creativecommons.org/licenses/by/4.0/

\begin{abstract}
As a goal of education and an effective approach to educational practice, learner autonomy is an integral part of learning of any kind. This survey aims at firstly confirming the results of previous study in the literature, and secondly disclosing more besides the existing results. Simulating the previous study on autonomy awareness made by the same author, this survey not only collects the attitudes of 80 college students by using the same questionnaire as previously, but also investigates the comments of 40 teachers, which is not included in previous studies. In addition, reflective self-reports by 4 of the students are also studied in this survey. This survey indicates that the results of previous studies are confirmed. However, it also shows that Chinese learners are ideologically ready but behaviorally not for autonomy in language learning. Four suggestions are put forward to foreign language teachers in China.
\end{abstract}

\section{Keywords}

Learner Autonomy, Autonomy Awareness, Cultural Differences, Attitude

\section{Introduction}

As a goal of education and an effective approach to educational practice, learner autonomy is an integral part of learning of any kind. Holec (1981: p. 3) defines learner autonomy as "the ability to take charge of one's own learning". Illés (2012: p. 509) regards it as "the capacity to become competent speakers of the target language who are able to exploit the linguistic and other resources at their disposal effectively and creatively". For Almusharraf (2018: p. 160), learner autonomy is "a learner's willingness to take taking responsibility for participating, applying, monitoring, and evaluating his/her learning, which is usually developed with the support of a teacher". Higgs (1988: p. 41) refers it to "process in which the learner works on a learning task or activity and is largely independent 
of the teacher who acts as manager of the learning program and as resource person". Although the definition of learner autonomy varies, according to Littlewood, they have usually included these central features:

- Students should take responsibility for their own learning.

- "Taking responsibility" involves learners in taking ownership (partial or total) of many processes which have traditionally belonged to the teacher, such as deciding on learning objectives, selecting learning methods and evaluating progress (Littlewood, 1999: p. 71).

Among many issues in promoting autonomy in language learners, there used to be a heated debate on whether autonomy is a Western concept and whether it suits those contexts in Eastern Asia is peculiar, especially when cultural differences are concerned. This paper is a report on my revised survey on autonomy awareness of foreign language learners in China. In the first part of the paper, I present the background of the survey, pointing out that a revised survey is conducted because I was not satisfied with the results of the first survey I made several years ago. In the second part of the paper, I briefly introduce the purpose of the new survey and put forward two hypotheses. I then elaborate on the method of the survey in part three and illustrate the results of the survey in part four. Based on the stuff in part four, I point out in part five that although the result of my previous survey is confirmed, the second survey also shows that Chinese learners in my survey do not behave as what they believed in. Therefore, I conclude in the last part that Chinese students seem to be ideologically ready but behaviorally not, for autonomy in language learning. I then end my paper with suggestions for foreign language teachers in China.

\section{Background of the Survey}

As Littlewood (1999: p. 71) points out, Autonomy in language learning is sometimes regarded as a Western concept which is unsuited to contexts, such as those in East Asia, as there is a difference in educational tradition in the above two cultures. Jones (1995: p. 228) sees autonomy as "laden with cultural values, especially those of the West" and unsuited to the traditions of learning and teaching in Cambodia. Ho and Crookall (1995: pp. 235-243) also report a similar situation in relation to students in Hong Kong. They point out that autonomy appears to contradict the teacher-centered, authority-oriented traditions of Chinese education in Hong Kong. Yasmin et al. (2020: p. 125) reports "sociocultural and psychological constraints" in Pakistan. Pierson (1996, cited by Lee, 1998: p. 282) characterized the typical Hong Kong Chinese learners as "passive, dependent, and lacking in initiative". Balla et al. (1991, cited by Lee, 1998: p. 282) also found that students in Hong Kong "have little incentive to undertake learning outside their studies".

However, not everyone agrees with the idea that autonomy is culture-specific. A case in point is Littlewood $(1999,2000)$, who claims after an ambitious world-wide investigation via questionnaires, that Asian students share similar learning attitudes and beliefs towards autonomy with their western counterparts. 
Enlightened by Littlewood's research, I did a similar investigation in mainland China (Qi, 2004), and confirmed Littlewood's claim, then I discussed its implication for language teaching in China in that autonomy in language learning was not "western", and that Chinese students needed autonomy on their way to be a competent English speaker. I also pointed out that a combination of group work with "reactive autonomy" might be a guideline for language teachers to promote autonomy in Chinese foreign language learners.

After my research made in 2004, from September 2004 to June 2010, I worked as the coordinator of two projects funded by the Ministry of Education of China, which aimed at reforming English language instruction model by means of the Internet and multimedia. In the new teaching model, learners were encouraged to learn in groups (which were defined by Boud, 1988 as group-centered approach); under the supervision of the teacher (which Littlewood, 1999 defined as reactive autonomy). what my colleagues and I saw and heard was not what we had expected: The group discussions among our students were either noisy with Chinese language, or quiet with somebody occasionally spoke out one or two English words; some of them complained that the group works were usually dominated by some "excellent students", some said they would rather the teacher tell them what they should learn instead of letting them to explore on their own.

The experience in the forementioned two reform projections keeps me reflecting on both Littlewood's $(1999,2000)$ and Qi's (2004) investigation, together with the literature I reviewed above that points out learner autonomy may be culture-specific (Littlewood, 1999; Jones, 1995; Ho \& Crookall, 1995; Yasmin et al., 2020). Moreover, the results of Littlewood's (1999, 2000) and Qi (2004) investigation only indicate that Chinese English learners share similar attitudes towards learner autonomy with their Western counterparts, which may not necessarily result in their actual behavior. Maybe the respondents to my questionnaire did not say what they really thought, maybe it is a cultural practice of Chinese to say "YES" while to do just the opposite. I decided to find out more. The next sections elaborate on my new research on the "old" topic.

\section{Purpose of the Survey}

The purpose of this survey is to expose: 1) whether my previous study in 2004 was valid and; 2) whether students behave as what they believe in. Correspondingly I have two hypotheses: 1) The result of my previous study, together with that of Littlewood's (1999, 2000) is valid (Questionnaire for Students); 2) Students do behave as what they believe in (Questionnaire for Teachers, and self-report by 4 students).

\section{Method}

A survey was conducted with 80 Chinese tertiary students and 40 college English teachers, with two questionnaires and a controlled self-report based on questions 
for 4 students randomly selected from the questionnaire participants. The questionnaires (Questionnaire for Students and Questionnaire for Teachers respectively, with the only difference in subject "I" and "They") were designed to measure the degree to which they agreed or disagreed with the statements I devised. The controlled self-report aimed at disclosing more detailed information related to the questionnaires. The following subsections give a brief description of the participants, the procedure and the research instrument of the survey.

\subsection{Participants}

The participants in my questionnaires were 40 first-year and 40 second-year college students and 40 College English teachers in Zhejiang Yuexiu University, P.R. China where I am working. Both the students and teachers were selected randomly among 7000 students and 60 College English teachers in that university. The first-year students had learned English for at least 6 years and were supposed to have grasped a vocabulary of at least 2400 , and the second-year students had learned English for at least 7 years and were supposed to have grasped a vocabulary of at least 3400 . Most of the teachers who participated in the survey are experienced, 18 (45\%) of whom had taught English for more than 10 years, $18(45 \%)$ of whom more than 5 years, and $4(10 \%)$ of whom more than 3 years.

\subsection{Research Instruments}

I reviewed my questionnaire that I used in my 2004 survey in Chinese, made very few revisions so that the content of the questionnaire did not change at all. I tried the "revised" questionnaire (Questionnaire for Students) again but less in the number of participants because I presumed that the result would not change over the years and the result of this will be less important than the next step. Meanwhile, I investigated the same content among teachers (Questionnaire for Teachers), hoping that they would disclose what the students actually do in and outside the classroom, which might not be consistent with what the students claimed to be. In both questionnaires, participants were asked to score each statement with 5 if they strongly agreed, 4 if they agreed, 3 for neither agreed or disagreed, 2 for disagreed and 1 for strongly disagreed. Then I asked 4 volunteers from the participants to write a self-report each, I devised questions that were based again on the same content as the questionnaires, and were supposed to elicit more detailed reflection on why sometimes students did not behave as what they believed in.

\section{Analysis and Results}

80 questionnaires were delivered to students and 67 valid data were collected, 40 questionnaires were delivered to teachers and we collected 37 valid responses. Statistical analyses were based on software Excel and SPSS. Independent-Samples $\mathrm{T}$ Test was applied in dealing with all the data from both students and teachers at Zhejiang Yuexiu University. 


\subsection{The Result of Same Questionnaires Conducted in 2004 and} 2021

Table 1 below shows the result of the same statements conducted respectively in 2004 and 2021. The data below indicates that Chinese students in different years share similar opinions on their attitudes towards autonomy in language learning, motivation, and teacher authority and so on.

\subsection{The Result of the Same Questionnaire from Both Students and Teachers in 2021}

Based on Littlewood's analysis (Littlewood, 1999, 2000), I (Qi, 2004: p. 92) grouped the above 10 statement into 4 categories: Statements 1, 2, and 3 represent students' willingness to take part in group work, which is essential character of an autonomous learner; statements 4 and 10 can be called their care for accuracy, which is a constraint for an active learner; statements 5, 6, and 7 represent their respect to authorities, another constraint for a proactive learner; and statements 8 and 9 indicate their motive to learn, which determines whether a learner will take initiative in learning. To save space in tables, I just briefly defined them as "Willingness", “Accuracy", "Authority" and "Motivation" respectively.

Table 1. Comparison of autonomy awareness of Chinese college students in 2004 and 2021.

\section{Statements}

Mean Mean

(Qi, 2021) (Qi, 2004)

1) I like activities where I am part of a group which is working towards common goals.

$3.88 \quad 3.85$

2) I like to take part in activities which involve discussion within a group.

$3.84 \quad 3.64$

3) When I am working in a group, I like to help maintain a sense of harmony in the group.

4) In the open classroom, I often feel hesitant to "stand out" by voicing my opinions or questions.

5) In the classroom I see the teacher as an authority figure.

6) I tend to see knowledge as something to be "transmitted" by the teacher rather than "discovered" by me as a learner.

$2.21 \quad 2.03$

7) I expect the teacher (rather than me myself) to be responsible for evaluating how much I have learnt.

8) I feel strong motivation to follow through learning tasks of which I perceive the practical value.

9) I feel more motivated to work when my own success contributes to the goals or prestige of significant groups (e.g. family, other students).

10) In the classroom I feel very concerned to perform well and correctly in what I do. 
Table 2 and Table 3 below tell the difference between students' attitudes towards autonomy and teachers' comments on the students' behavior in each question. As can be seen from the tables, although students claim that they do not quite mind whether they make mistake in their performance in class (3.38), that they do not quite see the teacher as an authority figure (2.51), and they are motivated to learn (4.24), their teachers, however, their actual behavior in class as revealed by the teachers, does not fully agree with what the students claim. The only category teachers agree with the students is that students are active in group work and that students are cooperative in group work.

\section{Discussion}

My discussion of the results of my "revised survey" will start from "revisedness". I "revised" it because I used to do the similar survey before. I used the same (with slight adaptation in Chinese version in the second time) questionnaire in both surveys. The differences lie in the purpose and method of the revised survey, which have been introduced in detail in Sections 4 and 5. In the next subsections, I will discuss the result of my revised survey in accordance with the hypothesis I set in Section 4.

Table 2. Comparison of students' attitudes and teachers' comments by statements.

\begin{tabular}{|c|c|c|}
\hline Statements & $\begin{array}{c}\text { Mean } \\
\text { (Students') }\end{array}$ & $\begin{array}{c}\text { Mean } \\
\text { (Teachers') }\end{array}$ \\
\hline $\begin{array}{l}\text { 1) I like activities where I am part of a group which is } \\
\text { working towards common goals. }\end{array}$ & 3.88 & 3.73 \\
\hline $\begin{array}{l}\text { 2) I like to take part in activities which involve discussion } \\
\text { within a group. }\end{array}$ & 3.84 & 3.78 \\
\hline $\begin{array}{l}\text { 3) When I am working in a group, I like to help maintain } \\
\text { a sense of harmony in the group. }\end{array}$ & 3.76 & 3.78 \\
\hline $\begin{array}{l}\text { 4) In the open classroom, I often feel hesitant to } \\
\text { "stand out" by voicing my opinions or questions. }\end{array}$ & 3.09 & 4.00 \\
\hline 5) In the classroom I see the teacher as an authority figure. & 2.75 & 3.57 \\
\hline $\begin{array}{l}\text { 6) I tend to see knowledge as something to be } \\
\text { "transmitted" by the teacher rather than "discovered" } \\
\text { by me as a learner. }\end{array}$ & 2.21 & 3.49 \\
\hline $\begin{array}{l}\text { 7) I expect the teacher (rather than me myself) to be } \\
\text { responsible for evaluating how much I have learnt. }\end{array}$ & 2.58 & 4.08 \\
\hline $\begin{array}{l}\text { 8) I feel strong motivation to follow through learning } \\
\text { tasks of which I perceive the practical value. }\end{array}$ & 4.30 & 4.08 \\
\hline $\begin{array}{l}\text { 9) I feel more motivated to work when my own success } \\
\text { contributes to the goals or prestige of significant } \\
\text { groups (e.g. family, other students). }\end{array}$ & 4.18 & 3.97 \\
\hline $\begin{array}{l}\text { 10) In the classroom I feel very concerned to perform } \\
\text { well and correctly in what I do. }\end{array}$ & 3.67 & 3.70 \\
\hline
\end{tabular}


Table 3. Comparison of students' attitudes and teachers' comments by categories.

\begin{tabular}{|c|c|c|c|c|c|c|}
\hline Categories & Response & $\mathbf{N}$ & Mean & $\begin{array}{c}\text { Std. } \\
\text { Deviation }\end{array}$ & $\mathbf{t}$ & $\begin{array}{c}\text { Sig. } \\
\text { (2-tailed) }\end{array}$ \\
\hline \multirow[b]{2}{*}{ Willingness } & Students' response & 201 & 3.83 & 0.80 & \multirow[b]{2}{*}{0.73} & \multirow[b]{2}{*}{0.47} \\
\hline & Teachers' response & 111 & 3.77 & 0.63 & & \\
\hline \multirow[b]{2}{*}{ Accuracy } & Students' response & 134 & 3.38 & 0.91 & \multirow[b]{2}{*}{$-3.65^{\star *}$} & \multirow[b]{2}{*}{0.00} \\
\hline & Teachers' response & 74 & 3.85 & 0.86 & & \\
\hline \multirow{2}{*}{ Authority } & Students' response & 201 & 2.51 & 0.83 & \multirow{2}{*}{$-12.59^{* *}$} & \multirow{2}{*}{0.00} \\
\hline & Teachers' response & 111 & 3.71 & 0.76 & & \\
\hline \multirow{2}{*}{ Motivation } & Students' response & 134 & 4.24 & 0.64 & \multirow{2}{*}{$2.23^{*}$} & \multirow{2}{*}{0.03} \\
\hline & Teachers' response & 74 & 4.03 & 0.68 & & \\
\hline
\end{tabular}

* indicates the difference is significant, ${ }^{* *}$ indicates the difference is very significant.

\subsection{Hypothesis One Is Accepted}

In order to verify my first hypothesis (the result of my previous study, together with that of Littlewood's $(1999,2000))$, I used the same method and instrument as I did in 2004. Firstly the figures in Table 1 are very near to each other; secondly, although it has been 17 years since my first survey, there can hardly be striking difference in their learning attitudes of Chinese college students; lastly and maybe mostly importantly they both echo the survey result by Littlewood $(1999,2000)$ in that Asian students share similar attitudes towards autonomy (learning attitude) with students outside Asia.

\subsection{Hypothesis Two Is Rejected}

It is fair to say that verifying hypothesis one is not the ultimate purpose of the survey. As is mentioned in section 3 of this paper, in order to find out the reason why my students did not behave as they thought they ought to do or are likely to do (Qi, 2004), I made two inferences (maybe the respondents to my questionnaire did not say what they really thought, maybe it is a cultural habit of Chinese to say "YES" while to do just the opposite). The results of table one has rejected my first inference.

However, the results of Table 2 and Table 3 might have given hints on whether students do as what they believe in. For the questionnaire I gave to the teachers, I deliberately changed the subject of each statement from "I" to "They", as I am quite convinced that teachers' responses to these statements will mirror what students do in and outside classroom. Thus, students' response to my questionnaire will be "what they believe in", while teachers' response to my questionnaire will be "what the students behave". Unfortunately, the students do contradict in their belief and behavior. A good case in point is in their respect to authority figures as indicated in Table 3. 


\subsubsection{Contradiction in Respect to Authority}

When the teacher is regarded as an authority figure, the students are inclined to strictly follow his or her directives and instructions and are therefore less likely to take charge of their own learning.

The students claim they do not quite think of the teacher as an authority figure, and therefore they will not rely on the teacher to "transmit" knowledge and evaluate their learning result (2.51). Worthy of notice is also in Table 2, 2.75 for statement 5, 2.21 for statement 6 , and 2.58 for statement 7 . But the teachers' responses to the pertinent category or statements are 3.71 in Table 3, 3.57, 3.49, and 4.08 respectively in Table 2, indicating a very significant difference from what the students claimed. In other words, what the students behaved is significantly different from what they believe. The students' self-reports also reveal the difference. Two students (Fan and Zheng) admit they do not see the teacher as an authority; they will sometime disagree with what the teacher say in class, but seldom speak out. The third student (Wang) expresses similar attitude, adding she will use indirect language when she challenges the teacher. The fourth student (Dai) seems to deliberately avoid the question by saying that he does think of the teacher as an authority figure and something else.

Therefore, it may conclude from the above discussion that the students don't see the teacher as an authority figure, but they also respect the teacher, so much so that they behave as if they take the teacher as an authority. China is a nation with long tradition in respecting the teacher. It is also highly valued if students regard their teachers as their "second parents". A good example can be found in a Chinese saying: "A teacher of yours a day, a parent of yours all life". So, respecting teachers is, in Schwartz's word (Schwartz, 1992, cited in Fischer, 2006), a "cultural norm" in China. Meanwhile, with the rapid development in economy and inter-cultural communication, more and more Chinese young people are so "westernized" that for Chinese students today, "it is not just a question of how being Chinese affects me, but also how 'Chinese' do I feel I want to be at any time." (Gieve \& Clark, 2005: p. 264). The difference between belief and behavior may be a result of Students' dilemma in choosing how to behave in a Chinese context.

\subsubsection{Contradiction in Respect to Accuracy}

When the students care too much about "being accurate", they will be afraid of making mistakes and are therefore less likely to take initiative in learning, especially in such activities as speaking out in class.

Students claim in statement 4 in Table 2 that they do not quite (neither agree nor disagree) hesitate in speaking in class (3.09), but their actual behavior according to the teachers, indicate that they do (4.00). The second category (Accuracy) in Table 3 also reveals a very significant difference between what the students believe and what they actually behave. A further study into the self-reports by the 4 students mentioned above reveals the reasons why they care a lot while speaking in class. Everyone admits that they care because they are afraid of "los- 
ing face", or "being laughed at". This may appear to be odd when the students' willingness in work group and their motive to learn English are considered.

Tedeschi (1990, cited in Pellegrino Aveni, 2005: p. 15) defines two terms of self: "real self" and "ideal self" in the development of power and self-esteem in small children. I think in the development of foreign language competence, the learners may also have two "selves", the "ideal self", models of successful English learners who they wish to be, and the "real self", constructed on their way to success. According to Pellegrino Aveni (2005: p. 15), "if a learner perceives that L2 use will threaten her self-presentation, thereby increasing the discrepancy between the real self and the ideal self, he or she is less likely to use the L2". The students have the motive to learn English all right (which will be discussed in detail in the following part), at the same time, once they feel their "real self" threatened (loosing face, or being laughed at), they either feel very concerned to perform well and correctly in what they do, or feel hesitant to "stand out" by voicing their opinions or questions.

\subsubsection{Contradiction in Respect to Motivation}

Undoubtedly a more highly motivated learner is more likely to be an autonomous learner.

The results of my survey in motivation are a bit tricky in that both students and teachers think the students are motivated to learn English ( 4.24 by the students and 4.03 by the learners in Table 3), but the statistical result showed there was significant difference between the two numbers. Nevertheless, one thing is certain that the degree in motivation the teachers commented on the students were different from what the students claimed to be. Hints may also be found in the self-reports by the students and criticism to foreign language education policy in China.

Of the four students who wrote the self-reports, three (Fan, Wang, and Dai) say their motive to learn English is to be able to communicate with foreign cultures and they feel strong desire to learn English, only one of them (Zheng) says though she used to think by learning English she could communicate with people of different culture better, she now thinks, after years of frequent tests and examinations, her main goal to learn English is to pass examination. She even wonders whether she will go on learning English after she has passed all the necessary examinations and graduated from college.

In the past few years, there was growing criticism to the Chinese foreign language education policy, especially to the nationwide college English examinations Band Four and Band Six. To mention a few in the literature, Jin (1999), Niu (2001), Han, Dai and Yang (2004) pointed out two problems with current Chinese foreign language education policy: examination-centered and low in validity and reliability of Band Four and Six.

Even though the students claim that their motive to learn English is not to pass the examinations, as long as they hope to graduate from college, they can hardly escape being examined time and again in their college years. Marton and 
Saljo (1984, cited in Boud, 1988: p. 36) report that "when students perceive themselves to be under threat this (assessment) encourages surface approaches to learning." It might be the "surface approach to learning" in reality that leads to the disagreement on the degree in students' motivation, that is, the teachers in the survey did not think the students as motivated as they themselves claim to be.

\subsubsection{Agreement in the Willingness to Take Part in Group Work}

Autonomous learners tend to be more willing to take an active part in group work than those who are less autonomous.

The only agreement in students' belief and behavior seems to be in their willingness in take part in group work (Table 2 and Table 3). However, an exploration into the students' self-reports does not find so much positive information as expected. Although every student expresses his or her willingness to be cooperative in group work, two students (Fan and Wang) say they enjoy group work and only one student (Fan) says she often takes an active part in it. The other three (Zheng, Wang, and Dai) say they do not actually take an active part in group work because they can hardly say much in English, sometime they remain silent in case that they will not "loose face" or "be laughed at".

Worthy of mention is the fact the students actually use terms like "losing face", or "being laughed at" several times in their self-reports. Similar to explanation in 6.2.2, I presume that the students are willing to take part in group work, but their fear for losing "real self" prevents them from being an active participant.

\section{Conclusions and Implication}

The debate over the question whether autonomy in language learning is a western concept still goes on (for example, Gieve \& Clark, 2005; Fischer, 2006; Helwig, 2006; Yasmin et al., 2020). The revised survey I conducted recently is not intended to put an end to the debate. Although the limited samples in my survey could hardly illustrate the whole picture of the situation, it might have given some clues as to how to treat the data collected from an Eastern Asian context like China. Littlewood $(1999,2000)$ and I are right when we both agree that students in Eastern Asian context shared similar attitudes with their Western counterparts. However, that alone does not necessarily mean that the students will behave as what they believe in. Although I am not sure whether the same thing happens elsewhere, especially in the West, I do find in my revised survey that Chinese students seem to be ideologically ready but behaviorally not for autonomy in language learning. They don't see the teacher as an authority figure in mind but they do in practice; they know they should not care too much about accuracy in class but they do perform cautiously for fear of "losing face" or "being laughed at"; they claimed themselves to be highly motivated (for communicative purpose), yet they can hardly escape the shackle of examination-centered Chinese foreign language teaching policy and therefore involve themselves in 
"surface approach to learning" mentioned in my discussion; they are willing to take part in group work, but meanwhile they also admit that they feel that their "real self" threatened when they speak in English.

So, based on the discovery of the revised survey, the following suggestions are given to teachers of English in China:

First, it is not bad news that students do not see teachers in language class as authority figure. If we teachers take it as a hint that the students would like to take more responsibility in learning, and do give them appropriate freedom in making decisions in learning, then Chinese students will be more independent.

Second, students do care about accuracy when speaking in class. That's true when you think about their fear in losing face or in being laughed at. But doesn't that mean, if teachers are more tolerant to the mistakes the students make, if teachers keep encouraging students to speak more bravely (after all making mistakes in learning English is by no means a shame at all), the students will have more confidence in themselves?

Third, a serious situation that every student and teacher in China needs to face is all kinds of examinations. Unfortunately, English may be the subject that is most frequently tested. It may not be teachers' fault. After all, one of the purposes of a test or examination is to facilitating learning rather than to threaten it. If teachers can help the students realize that, or if teachers call on the government more frequently to take measures to reduce to negative effect of examinations on foreign language learning and teaching, the motives of students to learn may be more integrative rather than be both instrumental and surface-oriented.

Last if not least, the fact the students like to take part in group work should be encouraged. Besides, it's important for teachers to create a "facilitating environment" as described by Ryan (1991: pp. 208-238), that is, to provide concrete support through help and resource, to provide personal concern and involvement in group work, to offer opportunities to the students in making choices, and to make students aware that they are not controlled by any external agent including teachers.

\section{Conflicts of Interest}

The author declares no conflicts of interest regarding the publication of this paper.

\section{References}

Almusharraf, N. (2018). English as a Foreign Language Learner Autonomy in Vocabulary Development Variation in Student Autonomy Levels and Teacher Support. Journal of Research in Innovative Teaching \& Learning, 11, 159-177.

https://doi.org/10.1108/JRIT-09-2018-0022

Boud, D. (1988). Moving towards Autonomy. In D. Boud (Ed.), Developing Student Autonomy (pp. 17-39). Kogan Page.

Fischer, R. (2006). Congruence and Functions of Personal and Cultural Values: Do My Value Reflect My Culture's Value? Personality and Social Psychology Bulletin, 32, 
1419-1431. https://doi.org/10.1177/0146167206291425

Gieve, S., \& Clark, R. (2005). “The Chinese Approach to Learning”: Cultural Trait or Situated Response? The Case of Self-Directed Learning Programme. System, 33, 261-276. https://doi.org/10.1016/j.system.2004.09.015

Han, B., Dai, M., \& Yang. L. (2004). A Survey on Issues in College English Testing. Foreign Languages and Their Teaching, 179, 17-23.

Helwig, C. C. (2006). The Development of Personal Autonomy. Cognitive Development, 21, 458-473. https://doi.org/10.1016/j.cogdev.2006.06.009

Higgs, J. (1988). Planning Learning Experiences to Promote Autonomous Learning. In D. Boud (Ed.), Developing Student Autonomy (pp. 40-58). Kogan Page.

Ho, J., \& Crookall, D. (1995). Breaking with Chinese Cultural Traditions: Learner Autonomy in English Language Teaching. System, 23, 235-243. https://doi.org/10.1016/0346-251X(95)00011-8

Holec, H. (1981). Autonomy and Foreign Language Learning. Pergamon Press.

Illés, É. (2012). Learner Autonomy Revisited. ELT Journal Special Issue, 66, 505-513. https://doi.org/10.1093/elt/ccs044

Jin, S. (1999). The Reason Why College English Education in China Is Both Time-Consuming and Inefficient. Foreign Language Teaching and Research, 31, 21-23.

Jones, J. F. (1995). Self-Access and Culture: Retreating from Autonomy. ELT Journal, 49, 223-234. https://doi.org/10.1093/elt/49.3.228

Lee, I. (1998). Supporting Greater Autonomy in Language Learning. ELT Journal, 52, 282-289. https://doi.org/10.1093/elt/52.4.282

Littlewood, W. (1999). Defining and Developing Autonomy in East Asian Context. Applied Linguistics, 20, 71-94. https://doi.org/10.1093/applin/20.1.71

Littlewood, W. (2000). Do Asian Students Really Want to Listen and Obey? ELT Journal, 54, 31-36. https://doi.org/10.1093/elt/54.1.31

Niu, Q. (2001). Issues in Current Foreign English Language Testing. Foreign Language Teaching and Research, 33, 140-143.

Pellegrino Aveni, V. A. (2005). Study Abroad and Second Language Use. Cambridge University Press. https://doi.org/10.1017/CBO9780511620584

Qi, H. B. (2004). A Survey on Autonomy Awareness of Second Language Learners in China Foreign Language Education. Language Teaching, 25, 90-92.

Ryan, R. M. (1991). The Nature of the Self in Autonomy and Relatedness. In J. Strauss, \& G. R. Goethals (Eds.), The Self: Interdisciplinary Approaches (pp. 208-238). Springer. https://doi.org/10.1007/978-1-4684-8264-5_11

Yasmin, M., Naseem, F., \& Abas, N. (2020). Constraints to Developing Learner Autonomy in Pakistan: University Lecturers' Perspectives. Educational Research for Policy and Practice, 19, 125-142. https://doi.org/10.1007/s10671-019-09252-7 